\title{
Is maritime transport an urban network? The interplay between global container flows and urban hierarchies
}

Draft version of the chapter published in Neal Z.P., Rozenblat C. (Eds.) (2021), Handbook of Cities and Networks, Edward Elgar Publishing, pp. 449-471.

\author{
César Ducruet \\ Centre National de la Recherche Scientifique (CNRS) \\ UMR 7235 EconomiX, Nanterre, France \\ Email : cesar.ducruet@economix.fr
}

\begin{abstract}
Maritime transport largely supports international trade and has long been seen as a vital element of economic and urban development. Since the 1950s, however, the emergence of containerization is generally believed to have transformed the spatial and functional organization of human settlements. Increasingly powerful global transport actors combined with the skyrocketing size of containerships led to unprecedented optimality, concentration, and selection among port cities. The latter are thus both constraints (land-use, congestion) and facilitators (production, consumption) of port and shipping activities nowadays. This chapter wishes to further understanding how have cities maintained their position in the global shipping network. It complements a wider reflection about places, scales, and networks by an empirical analysis of global shipping flows in relation to urban population, testing the hypothesis that cities and container shipping remain mutually essential nowadays.
\end{abstract}

Keywords: container shipping; globalization; maritime transport; network analysis; port cities; urban development

\section{Introduction}

Since the 1950s and 1960s already, systematic approaches to the diffusion of various flows (information, people, goods) and especially, innovations across urban networks (or systems of cities) have emerged in geography and regional science. Both U.S. and European (Sweden, France) scholars, through direct or indirect collaboration, developed various conceptual frameworks and empirical case studies of urban networks in such respect (see Peris, 2016 for a review of this vast literature). However, such schools of thought evolved in different ways in later decades, resulting in a wider diversity of urban network studies and definitions. Yet those schools have in common to remain relatively abstract in scope, proponing their own theories and concepts, with limited transversal dialogues among them; when operated and applied empirically, the most common geographical scale to study urban networks remained at the national level (Ducruet and Lugo, 2013).

It is, perhaps, the P.A.R.I.S. team in France which innovated the most in a sense that its members gradually expanded the geographic scope of their initial French-based studies to the whole European continent, through analyses of cities connected by multinational firms (Rozenblat and Pumain, 1993) 
or by airline and railway networks (Cattan, 1995). These large-scale investigations questioned the influence of city size and specialization on the attractiveness of specific activities through a relational perspective, thereby reaching beyond the traditional analysis of technical networks and planar graphs in this discipline (Ducruet and Beauguitte, 2014). It is quite common nowadays, with the explosion of computer capacity and the adoption of new methodological tools related with simulation models and big data, to find global-level studies in the literature on urban networks of all kinds. Yet, this chapter would like to insist on a remaining "dark corner" within urban network research, namely cities connected by water, or maritime transport.

Such a claim may appear surprising given the long-term historical importance of the sea to connect continents, carrying vast amounts of goods but also people and information (Stopford, 2008), without which globalization would probably not have been possible (Frémont, 2007). It is often recognized in the literature that ports and cities evolved from synergy to independence due to several factors. On the urban side, cities diversified their economy through successive innovation cycles (Pumain et al., 2009) to such an extent that for many port cities, maritime transport became a minor function (Bretagnolle, 2015), leading to port area dereliction, waterfront redevelopment, and to the construction of modern port terminals away from urban areas to mitigate environmental and land-use issues (Merk, 2013). On the port side, there are numerous evidences that port functions have changed in ways incompatible with inner-city location, with the expansion of hinterlands (i.e. the inland market area of the port), growing trade and cargo handling volumes, and increased productivity and efficiency resulting in lack of space, reduced labor and economic impacts, increased specialization, and the need for shifting towards more accessible locations to adapt ever-increasing ship sizes. In many disciplines such as geography, history, regional sciences, and economics, it is now commonly recognized that ports have ceased to be an engine for urban growth in the contemporary era.

While such trends are well-documented through both spatial models of port-city evolution and numerous case studies since the 1960s already, there remains two unfinished debates on a) whether ports are still attached to cities and vice-versa; and b) about the specific role of the so-called "container revolution" in such a separation process. The first debate (a) remains because cities continue to be fed by material flows to grow and prosper (e.g. cement, gas, oil, various commodities, consumer goods), and maritime transport still carries about $90 \%$ of world trade volumes nowadays (UNCTAD, 2017). Feeding cities with such flows means that the physical separation does not necessarily implies a functional separation, at least for the international part of their trade (with other cities). Another argument was to say that port-city separation was not a universal phenomenon but mainly Western, given the strong permanency of such linkages in Asia for instance (Lee et al., 2008). A rise of interest for the geography of material flows in recent years led to a number of arguments in favor of maintained port-city and port-region interdependencies, either through quantitative (Ducruet and Itoh, 2016) or qualitative (Hesse, 2013) research. Yet, when shipping is seen through the lenses of firms networks and Maritime Advanced Producer Services (e.g. brokering, insurance, law, etc.), Jacobs et al. (2011) confirmed earlier works by demonstrating that the location of such activities is better determined by urban (population, presence of other APS, etc.) rather than port (traffic) variables.

The second debate (b) originates from the widely common belief that the introduction and spread of containerization greatly modified the spatial distribution of shipping networks and port hierarchies. Initially a land transport technological advance, containerization is known to have been introduced in the mid-1950s in the port and shipping sector in the United States by Malcolm McLean (1935-2001), head of a truck driving company, to speed up cargo handling operations using a standard "box", with the effect of reducing queuing time and congestion at the docks (Levinson, 2008). Pallets and all sorts of (mainly) manufactured goods were placed in such containers, thereby reducing freight 
transportation costs and transit times. However, containerization did not spread immediately to the rest of the world, due to resistance amongst port communities and shippers, as it is only in the late 1960s that its adoption started in a few European ports such as Antwerp (Morel and Ducruet, 2015). It is only from the 1970s that containerization truly took off and spread globally through successive diffusion waves (Guerrero and Rodrigue, 2014), from the U.S. to Europe, Japan, and through a joint process of geographic proximity (or contagion) and hierarchy (or economic welfare) throughout the world. In a context of growing global trade, containerization was recognized to have been a catalyzer of international exchanges (Bernhofen et al., 2013). It favored economies of scale in terms of port traffic concentration and increasing vessel size (Cullinane and Khanna, 2000), especially with the introduction of hub-and-spokes systems in the mid-1990s in certain regions with the emergence of transshipment hubs at intermediate locations as well as inland (or dry) ports and terminals to foster freight distribution through intermodal services (Rodrigue and Notteboom, 2010). Horizontal integration (mergers and acquisitions among shipping lines) and vertical integration (among different supply chain actors, such as a shipping line like Maersk getting involved in port operations through terminal concessions and even landside logistics) reinforced such a process, with still continues today. The global financial crisis (2008-2009) causing overcapacity in container shipping, an even more restrained handful of global actors concentrated the bulk of port and shipping operations through alliances and kept increasing vessel size while limiting vessel speed for the sake of fuel and labor cost saving. All these changes even more impacted the way port cities can handle such very selective megaships. Faster intermodal transfers away from urban centers accelerate the port-city spatial divide, large ports being built and operated far away to exploit lower land rents and larger space for expansion. Very few port cities, such as in Asia mainly, were able to maintain such a huge physical operations activity within the urban area due to political and spatial constraints (e.g. city-states, small countries, islands) such as Hong Kong, Singapore, but also Busan and Kaohsiung, the Asian "dragons" (Lee and Ducruet, 2009).

Nevertheless, a number of elements motivate this chapter to go one step further in the understanding of how containerization truly changed the longstanding ties between cities and maritime networks. And this is where comes the second debate (b) that is the basis of our discussion here, based on three main arguments. First, containerization is not the first technological innovation in the history of shipping, bearing in mind the previous transition from oar to sail in Greek antiquity (Rivers et al., 2015) or much later, the one from sail to steam (Bunel et al., 2017) and then from steam to combustion and specialization. The port selection process of containerization described by so many scholars is not so much different from the one documented, for instance, by Marnot (2005) in his work on technological change and port competition in the $19^{\text {th }}$ century, concluding that "recent transformations are perhaps less different [than older ones] by their nature than by their scale". Second, a recent empirical work on the topic of cities and maritime networks in general (Ducruet et al., 2018) concluded that the decreasing correlation between city size and traffic size did not coincide with the introduction of containerization, as it started much earlier, in the 1930s (see Figure 1).

[Insert Figure 1 about here]

While the transition from sail to steam did not have obvious effects on the correlation between population and number of vessel calls (all ships included), it is more the transition from steam to combustion that seems to have caused the decline. Therefore, containerization did prolong rather than cause port-city disconnection, contrary to the aforementioned belief, as part of a wider process of 
vessel specialization with increasing speed, size, and greater autonomy from natural conditions and combustibles (cf. coal stations replaced by fuel). Third, recent years witnessed a "return of the port into the city" (El Hosni, 2017), especially for container terminals. Although this process does not (yet?) apply to a majority of large port cities, it is perhaps symbolic that it started in London, once the world's largest port, through the construction by the global operator Dubai Ports World (DPW) of the London Gateway project within the Greater London area, thereby competing with the Hong Kong-based operator Hutchinson Whampoa (HPH) located in Felixstowe, a small town of about 3,000 inhabitants situated about 300 kilometers from London city, using the slogan "ship closer, save money" to attract warehouses, shippers, and related flows around the brand new container terminal. A similar phenomenon was observed in Jakarta, Taipei, Osaka, and Tokyo. While the latter initiatives (i.e. creating or expanding the container port of the countries' largest cities) were more based on government intervention, they have in common with London the effect of reducing trucking distance and related carbon emissions. This new phase of port-city evolution might become a model for other large cities served by distant container terminals after successive phases of physical and functional disconnection. In addition, relatively large cities compared with the European average, such as Antwerp and Hamburg, have managed to overcome all the difficulties of their upstream location to maintain among the highest levels of port activity, being Europe's second and third largest container ports today and have been so for decades (Notteboom, 2016).

The remainder of this chapter is as follows. The following section presents the data and methodology used for an empirical investigation into the spatial distribution of container shipping flows and networks across the global urban hierarchy from the 1970s to nowadays. Next, we present our main results with the main hypothesis that container shipping still remains tied to cities in one way or another, despite all the contemporary changes that apparently altered their initial symbiosis. We discuss such outcomes in the conclusion section by addressing how this study can improve our understanding of transport systems, urban networks, and spatial change in geography and other disciplines.

\section{Constructing a global urban network made of container shipping flows}

\subsection{Methodological specifications}

While Figure 1 served as a long-term view on the evolution of port-city relationships, it was based on the number of vessel calls including all types ships. In this chapter, we particularly focus on container shipping, because such flows are believed to have a specific spatial distribution compared with other types of vessels for the reasons cited above. A handful of previous works demonstrated that container flows, which carry the most valuable goods and are operated through regular, scheduled services, keep being concentrated in the richest and most productive port regions specialized in the tertiary sector (Ducruet et al., 2015), while being much overlapped with other maritime layers (e.g. passengers and vehicles, solid and liquid bulks, and general cargo) due to a path-dependent and place-dependent process (Ducruet, 2013); in other words, containerization did not spread randomly but at ports already diversified in other commodity types.

This chapter wishes to go more in-depth into the verification of how are container flows maintained (or not) their ties with the global urban hierarchy. To achieve such an objective, it is imperative to measure both container flows and urban variables. We collected vessel movement data from the world's leading maritime insurance company (Lloyd's List Intelligence) on the basis of two complete months of inter-port vessel flows each year (i.e. June and December) over the last four decades (19772016). Such flows were arranged in the form of a weighted origin-destination matrix with deadweight 
tonnage (DWT) as the measurement unit, which corresponds to the cargo carrying capacity of vessels. Two network topologies are used in this paper to test our main hypothesis, usually known in the graphtheoretical literature as space- $L$ and space-P (see Figure 2); the first being restrained to direct movements among ports along the voyage of each vessel (i.e. Port1-Port2, Port2-Port3, Port3-Port4, etc.); the latter including indirect movements to take into account long-distance ties as well (i.e. Port1Port3, Port1-Port4, Port2-Port4, etc.). These two dimensions are interesting to compare in the case of maritime networks since they provide dramatically different results in terms of centrality measures for nodes, such as degree centrality and betweenness centrality. For instance, a large port like Shenzhen (China) in terms of total traffic volume - the factory of the world - has relatively fewer links to other ports (low degree) according to space- $L$ (direct neighbors), while in $s p a c e-P$, its belonging to multiple global and regional trade routes multiplies its connectivity (high degree). In other words, the space- $L$ topology gives more advantage to transshipment hubs in the network, while the space-P topology give more importance to trading ports. Transshipment (or transit, redistribution) and real trade are two important facets of port activity that are sometimes combined by the same nodes, such as Rotterdam and Hamburg for instance. When it comes to urban networks, we hypothesize that space-P shall be more relevant than space- $L$ to measure the relationship with city size.

[Insert Figure 2 about here]

Maritime container flows alone do not suffice to build an urban network. Still in the aforementioned matrices, nodes are ports and/or port terminals, without a proper urban dimension. This is the case of most (maritime) network research, which largely ignores, to date, the fact that such nodes are part of human settlements having their own, specific characteristics. Defining the "city" is a longstanding issue in geography and elsewhere. We adopted the methodology recently proposed by Ducruet et al. (2018) whereby each port or terminal is assigned to an urban area according to several criteria. Here also two main dimensions are taken into account to verify our hypothesis; we call them "port cities (level 1)" and "extended city-regions (level 2)". At level 1, ports and terminals are assigned to their host city based on their intra-urban location (or very close proximity) to a morphological urban area that may, in turn, contain one or more ports. These cities are the ones to directly handle cargo by their own infrastructural means. At level 2, ports and terminals (that may or not already belong to a port city) are assigned, depending on the case, to a larger, nearby, landward connected urban area, should it be another port city or a non-port city, either coastal or inland. As such and in Figure 2, the shipping network is composed of only ports and terminals as nodes; the port cities network (level 1 ) assigns ports to cities whenever possible (e.g. $A, B, H, G$ ) some of them containing more than one port $(E+F)$; and the extended urban network (level 2) takes into account the dependence of ports (and port cities) on larger and neighboring cities, located inland (D) or being already a port city $(A+B)$, such as in the case of a downstream port city being in the market area of a more (landward) centrally located city more upstream in the latter case.

These two dimensions are essential because they allow us grasping how container flows are spatially tied to cities, and check, indirectly, the role of land transport in this relationship, since many (large) cities have lost their port functions while being served by distant terminals, while others have been able to maintain this activity despite all the burdens associated with land-use conflicts and congestion. Numerous monographs and ideal-typical sequences (spatial models) describe such dynamics, but this chapter goes one step further examining the interplay between these four dimensions. 
Last but not least, assigning ports to cities remains insufficient to validate or not our hypothesis. Huge efforts were thus made to attribute demographic features to cities, as a proxy of their economic importance. While population may not always be correlated with the true level of urban economic activity, it has the merit to be comparable across space and time and available from several urban databases. We assembled and harmonized three complementary sources: Geopolis (Moriconi-Ebrard, 1994), Populstat (Lahmeyer, 2015) for the 1975-2000 period and World Gazetteer (Helders, 2012) for the year 2010 based on the same definition of morphological urban areas and measuring their number of inhabitants every five years between 1975 and 2010. Although container flow data is available on a yearly basis, we consider in this chapter that population has been more stable and the same year can be used for testing the correlation with container flows. For instance, population numbers in 1985 are related with container flows variables for the years 1983-1987, in 1990 for the years 1988-1992, etc. Container shipping variables are kept relatively simple: total traffic volume per city, degree centrality, betweenness centrality, clustering coefficient, and eccentricity. Container flow variables will be compared with population taking cities either individually (e.g. correlations) or grouped into six classes of demographic size (quantiles) to allow calculating the average score of each class and its evolution overtime. Quantiles based on a fixed number of cities per class are preferred to arbitrary population thresholds to get closer to the historical context of each year or period, as being a "large city" does not have the same meaning in the 1970s and in the 2010s. Enlarging the scope of the analysis from terminal/port to port city and extended urban area goes along with earlier work on the potential accessibility of cities as it includes, albeit indirectly, land transport (potential) flows in the delineation of such spatial entities (see: Bretagnolle et al., 1998; Rozenblat, 2004). It is in line with recent efforts pushing further the empirical delineation of hinterlands, which remains a nearly unsolvable issue in geography still today (Guerrero, 2014; Halim et al., 2016).

\subsection{Preliminary results}

In this part of the chapter, we describe the evolution of the global container shipping network according to the four dimensions explained above. It is useful to observe how the network has changed overtime and what is the effect of node aggregation (at the level of port cities or extended city-regions) on its overall topology, should it be space-L or space-P. We therefore created 10 matrices of inter-port and intercity container flows and computed the four main centrality scores for each of them. The effect of node aggregation has been discussed recently in the case of the Greek shipping network and is a promising research direction to understand the effects of shifting the study unit from port to urban area (Tsiotas and Polyzos, 2018). A similar but more empirical approach was proposed by Ducruet et al. (2011) when analyzing the combined container shipping and passenger airline network from an urban perspective to study centrality determinants and functional specialization. These authors proposed even three layers of analysis, from terminal to city and mega-region, demonstrating that higher levels of aggregation are better to understand the complementarity of networks in a multilayered system linking cities of the world (see also Parshani et al., 2010 for an earlier attempt). It is only in the next section that we run network-analytical methods to the container shipping network to reveal the relationship between cities and flows.

First and as seen in Figure 3, containership traffic has grown apace along the study period, notwithstanding a noticeable slowdown in the years 2008-2009 relative to the global financial crisis causing a fall in demand, trade and economic downturn, and turmoil in the ports and shipping sector. Traffic distribution per place type is interesting as it shows a regular increase, despite fluctuations, of the weight of level 2 (extended city-regions) but also of ports (non-urban ports), the first concentrating 
about $20 \%$ of total world traffic on average, from $18 \%$ in 1977 to $21 \%$ in 2016 , and the latter confirming the growing traffic outside urban areas, although with a small weight compared to port cities (level 1).

[Insert Figure 3 about here]

Calculating the (linear) correlation between urban population and vessel traffic shows a different picture of this evolution. Despite the huge concentration of world traffic in urban areas (especially, port cities) as seen in Figure 3, we observe in Figure 4 an opposite phenomenon, that is, the regular decline of the correlation for any city type, but especially for port cities (level 1). Actually, the correlation for port cities has never been highly significant, starting slightly above 0.4 in 1977 and regularly declining (despite a short-term increase in the years 2005-2008) to above 0.3 in 2016. This moderate and relatively stable correlation shows that containership traffic is not fully explained by city size, at least at level 1 . At the contrary, the same correlation for level 2 (extended city-regions), despite a similar decreasing trend, had been much more significant in the early period, oscillating around 0.65 , and stabilized around 0.45 during the last decade 2006-2016. This also means that urban areas have lost their power explaining container traffic, but enlarging the spatial unit had the effect of better explaining (nearly half) of this traffic. Another striking fact is that extended city-regions have started witnessing a decreasing relationship between population and traffic in the mid-1990s, exactly in a phase of emerging hub-and-spokes configurations in liner shipping, dramatically increasing vessel sizes, and optimization of routing schedules. The same correlation for cities altogether (combined levels 1 and 2 ) is more or less the average of these two tendencies, i.e. a regular rather than decline of the correlation from about 0.60 in 1977 to about 0.36 in 2016, which means a loss of nearly half of the significance of port-city relationships overtime.

[Insert Figure 4 about here]

Due to the fact that such aforementioned trends may be caused by the emergence of a few outliers, i.e. large ports in small cities or small ports in large cities, we adopted another perspective in Figure 5 where urban areas are grouped into five quantiles of the same sample amplitude (20\%), from the smallest (class 1 ) to the largest (class 5) cities. The class " 0 " corresponds to non-urban ports. The view based on a Bertin matrix intentionally ignores proportionality among the different rows, in order to better observe the behavior of each class overtime. The figure also compares level 1 ( $A$, top) and level $1+2(B$, bottom) to check for possible variations due to node aggregation.

In all cases, one first result confirms the overwhelming concentration of world container traffic among the largest cities (class 5), although it had declined from 83.6\% in 1977 to $78.1 \%$ in 2016 at level 1, and has increased from $93.2 \%$ in 1977 to $95.1 \%$ in 2016. This dominance confirms our intuition that the declining correlation observed in Figure 4 was caused by a few outliers rather than a structural and ineluctable decay of port-city relationships. It is, of course, also due to changes in world trade patterns whereby Western port cities have lost market share to Asian port cities in this period (see Appendix 1), while cities in old industrial countries witnessed stable or shrinking population contrary to those in emerging countries. 
The loss endured by the largest cities at level 1 still means that such places lost traffic to small ones due to well-known factors such as congestion and lack of space for further port expansion, but the loss remains relatively negligible. Traffic shifted to smaller cities of class 1,2, but also 4 in the late period, meaning that traffic growth has not always occurred away from large cities: class 4 gained $3 \%$ since 2007 while classes 1 and 2 only grew less than 1\% during the same period. The gain for the largest cities suggests that node aggregation had the effect of grasping the traffic of neighboring ports and port cities when focusing on the region's main urban center. This explains why non-urban ports (class 0 ), the smallest cities (class 1 ) and the medium-sized cities (class 3 ) have lost so much, given that they lie in the vicinity of a larger urban center (class 5). Yet, classes 2 and 4 witnessed substantial growth in the late period for the same reasons cited above; not all of the largest cities have remained capable of handling ever-increasing cargo volumes so that some of their traffic, at the same time, shifted towards less-urbanized areas, as already observed by Hayuth (1981) in his work on the "challenge of peripheral ports".

Level 1 (A) and level 1+2 (B) have two other common trends that need further discussion. One of them is the fact that smaller cities witnessed a growing traffic share during a decade or so since the mid1990s for the reasons cited above (route optimization, port selection and competition, mergers and acquisitions in the shipping sector, growing ship sizes etc.), especially medium-sized cities (class 3 ). The second common trend is the temporary growth of the traffic share of non-urban ports, despite by low numbers (class 0 ), in the middle of the study period, mainly due to the construction of new ports outside urban areas. Those ports are often coined "ports in the desert" of "pure transshipment ports", although the transshipment function may take place in densely populated urban areas such as Singapore (Slack and Gouvernal, 2015). The temporary dimension of their growth cannot obscure their absolute growth as seen in Figure 3, although many of them have been incorporated into extended city-regions given their traffic share decrease since the late 2000 s.

[Insert Figure 5 about here]

Analyzing the relationship between traffic and population distributions is meaningful in many ways, although it leads to somewhat contradictory evidences. Container shipping has been through huge technological and operational transformations during the study period, which are not reflected the same in relation to cities depending on the methodology or research angle. While correlation between traffic and population clearly faded away, the largest cities have maintained paramount importance in global shipping flows from the late 1970s to nowadays. Node aggregation had the effect of better understanding how (apparently) isolated ports and port cities belong to the market area of a larger and nearby city, coastal or inland, thus implying that road transport has also played an increasing role in connecting cities, directly or indirectly, to global shipping, as ports and cities may not always be "at the same place". The fact that larger cities maintained their prominence does not underestimate the role and impact of supply chain actors on traffic distribution, but it helps to balance the belief that cities and maritime transport (especially, container shipping) are no longer tied to each other today. We discuss further such issues in the light of a network perspective in the next section.

\section{Urban centrality in the global shipping network}


As in the previous section but for selected years only, we now dive into a multidimensional perspective on how network centrality relates with the urban hierarchy in various ways. Although it has been demonstrated earlier that total container vessel traffic (or weighted degree, strength index) is highly correlated with certain centrality measures (Deng et al., 2009), it is important to observe the evolution of this correlation overtime and for a wider set of measures. We first calculate the linear (Pearson) correlation between urban population and the four chosen centrality measures (Figure 6) and we compare the average centrality score of population quantiles based on the four dimensions: level 1 (port cities), levels $1+2$ (all cities), space-L, and space-P. While most earlier works on the global container shipping network remained rather static and did not address urban issues, we did run such an analysis for only five years from 1977 to 2016, i.e. providing a snapshot for every decade. We used TULIP ${ }^{1}$ to calculate centrality indices, a graph visualization software created by the University of Bordeaux (see Rozenblat and Mélançon, 2013 for a wide panel of applications). Adding more years would be better to observe a continuous trend but it has the effect of exponentially increasing the number of matrices to create and manipulate (i.e. $40 * 4=160$ ). Each selected year has the merit of not being influenced by a specific event; except, perhaps, for 1997 which witnessed the Asian financial crisis but it is an interesting year as it marks a rupture in technological and operational aspects for container shipping, in the middle of the study period. The year 2007 occurs before the global financial crisis and 2016 is the most recent data which was available at the time of this study.

\subsection{Correlation between network centrality and city size}

Among the four centrality scores analyzed in Figure 6, it is important to mention that we calculated the inverse value of the clustering coefficient while keeping zero values unchanged. This operation allowed avoiding a bias in the correlation whereby peripheral nodes often exhibit zero values while important hubs have values close to zero, especially in the space-L dimension that gives advantage to hub ports over trading ports (Ducruet and Notteboom, 2012). We could have done the same for eccentricity but the original measure has been kept since unlike the previous one it does not suffer from any bias, although the correlation with population should be interpreted inversely, i.e. values close to 1 mean peripherality and those close to zero suggest a strong (topological) proximity to other nodes.

Partly due to the absence of a temporal continuum in the analysis, it is not always possible to find a coherent trend in the evolution of correlations. However, and as observed previously for vessel traffic, space-P correlations are (almost) always more significant than space-L ones, just like level $1+2$ compared with level 1. In the first case (topology), the space-L network is more sparse than the space$P$ network so that space-L better reflects the service configuration of private actors than trade patterns (space-P). In the second case (node aggregation), extending the focus from the host city of the port (port city) to the extended city-region allowed analyzing more spatially and functionally comprehensive nodes, i.e. better reflecting the extent of the hinterland, the market area of the port(s). Yet in a number of cases, even the extended city-region remains a tiny part of a vast hinterland, such as large so-called load centers or gateway ports like Rotterdam and Hamburg reaching across several countries (Merk et al., 2013) through intermodal transport; Le Havre and Marseilles in France covering most of northwestern and southeastern regions, respectively (Guerrero, 2014).

Our results (Figure 6) for betweenness centrality, a global centrality measure (i.e. number of occurrences on shortest paths throughout the network), show similar trends than total vessel traffic

\footnotetext{
${ }^{1}$ http://tulip.labri.fr/TulipDrupal/
} 
(Figure 4). Overall, the correlation with population is fluctuating but mainly decreasing, although in the fourth dimension (space-P / levels 1+2) the decline started from relatively significant values in 1977 (0.41) to reach 0.32 in 2016, a value that is higher than any other value in other dimensions. Thus, cities as nodes in the global container shipping network have lost significance to other factors that are not tested in this chapter but can be listed intuitively such as efficiency and productivity in terminal operations, location on optimal routes, presence of vertically integrated supply chain actors, and quality / fluidity of intermodal infrastructure (Notteboom, 2004). This measure corresponds to the concept of intermediacy developed by Fleming and Hayuth (1994) to depict the ability of a transport node to become well-inserted in the service networks of global players (see also Slack, 1993). This explains why it is the most likely to decrease in relation to population, as it is closest to the logics and rationales of private actors' interests compared with urban and territorial factors. A perfect example is Singapore, where more than $80 \%$ of total container throughput is dedicated to transshipment (or transit), the rest being "real trade" flows (cf. the concept of "centrality" or "traffic generation power" of Fleming and Hayuth, 1994).

The other global measure, eccentricity, expresses the topological proximity to other nodes in the network. It exhibits an opposite trend compared with betweenness, as in most cases its correlation with urban population increased dramatically, except from the fourth dimension that lacks a clear trend despite more significant values than other dimensions. This opposite trend can be explained by the fact that although the world's major cities may not always be the crossroads of major shipping routes (cf. betweenness), the global shipping network evolved in ways beneficial to deliver the goods as close as possible to these main markets where consumers and producers concentrate. After all, it is the raison d'être of maritime transport in general and container shipping in particular to import and export most of the world's trade volume and value, but in order to maintain and improve such an objective, it had to transform itself into an ever more efficient system having its own operational logics that do not always overlap the spatial distribution of urban settlements - the local origins and destinations of imports and exports (many of these being located further inland). This apparent paradox can be well illustrated by the case of Algeria, where Algiers, the largest urban and capital city is also the country's main port, but it connects the global shipping network mainly through the transshipment hub port of Marsaxlokk (Malta), operated by the French shipping line and terminal operator CMA-CGM (Mohamed-Chérif and Ducruet, 2016). Vessel movement data makes it impossible to track which part of Marsaxlokk's traffic relates to Algiers, so that the trade continuum with the rest of the world is blurred, and the correlation between urban population and centrality, at least in the Mediterranean basin, is distorted by such transit flows through low-populated hubs like Marsaxlokk but also Gioia Tauro, Tarento, Cagliari in Italy, Algeciras and Valencia in Spain, Tangier-Med in Morocco, etc. Nevertheless, the eccentricity of Algiers is low (high proximity to the core of the network) because it is well connected to an important hub situated along the circumterrestrial trunk line where largest containerships operate. The impossibility, except for a few large ports, to know the precise share of transshipment versus trade in total port activity is so far a huge limitation to address port-city relationships.

[Insert Figure 6 about here]

The two other centrality measures are more "local" in a sense that degree centrality and clustering coefficient only consider topologically neighbor nodes. Degree centrality is the most correlated with population among all measures in Figure 6 , but it does not show any particular trend, or somewhat a 
kind of "fluctuating stability", but in most cases the value for 2016 is slightly higher than the value for 1977 , reaching a peak in the middle of the period (1997). The trend is almost the same for the (inverse) clustering coefficient, with a peak value in 1997, and slightly higher values in 2016 compared with 1977 in the case of space-P only this time. The inverse clustering coefficient expresses the ability of a node to act as a hub amongst its closest neighbors, but its correlation with urban population had remained somewhat fluctuating and stable, without showing any specific trend. Thus, the analysis of correlations shows that global measures are more interesting than local measures because they better express convergence or divergence between urban and port hierarchies than local measures, which relationship with population is fuzzier.

\subsection{Centrality distribution per city size classes}

Like in the previous section, we have calculated the average centrality score of cities for each of the four dimensions and for the same five years under investigation (Figure 7). We provide in Appendix 2 an overview of the sample size, average, minimum and maximum population of each quantile for each year. Results are strikingly straightforward, as the average centrality increases from class 1 to class 5 and this phenomenon is more and more clear overtime. This is even truer when shifting from one dimension to the other, from space-L / level 1 to space-P / levels $1+2$. Yet, in certain cases there is mixed evidence as smaller cities sometimes have higher average centrality than larger cities, especially among classes 1 to 4 , while the class of the largest cities (5) nearly always surpasses the other classes. In the last dimension (space-P / levels 1+2), classes 4 and 5 surpass other classes to a large extent, with the exception of average clustering coefficient that is superior for class 3 compared with class 4 . The largest cities are thus more likely to exert hub functions than other cities, but such functions are not linearly distributed across the urban hierarchy, since in many cases, small cities can perform this "footloose" activity depending on the port selection factors and strategies of transport actors, beyond the sole spatial and functional issues faced by large port cities (Slack and Wang, 2002).

Such results are mainly due to the fact that, as demonstrated earlier, the bulk of world container traffic concentrates in the last quantile (5), so that it is not so surprising to find higher centrality scores between the same thresholds, which are quite low compared with world average: the last quantile includes all cities having at least 200 to 300,000 inhabitants, thereby including most of the world's largest ports, up to the world's largest city (Tokyo) that surpasses 30 million inhabitants. The last quantile is thus characterized by a higher variance than other quantiles, which makes it rather unique and difficult to compare.

[Insert Figure 7 about here]

For a test, we have added Appendix 3 using more conventional urban population thresholds to check for the distribution of container traffic among those different classes than the quantiles. Still, the two largest classes (i.e. over 1 million inhabitants) concentrate about $70 \%$ of traffic on average, while the largest cities (over 5 million inhabitants) only concentrate about $32 \%$ on average, so that class 4 instead of class 5 is the most likely to concentrate highest centrality measures. Another evidence that still does not go against the quantiles method is the fact that the largest classes have not witnessed traffic decrease overtime. Instead, their share has even increased up to 2007, but in 2016, the fact that more population data was accessible and available, especially for the smallest cities, artificially reduced their 
share. We therefore can conclude that city size remains a good determinant of container shipping traffic and centrality, despite all the technological and operational changes that are so much described and analyzed in transport studies, with the belief that cities do not anymore play a role in the distribution of physical flows and supply chains.

\section{Discussion and conclusion}

This chapter tackled for the first time a difficult challenge, that is to verify whether maritime transport, and container shipping in particular, constitutes an urban network, like other networks that are so widely studied in the academic sphere and beyond, such as airlines, multinational firms, and other vectors of flows of all kinds should they be material or immaterial. By demonstrating that technological and operational change indeed modified the way ports and maritime networks are tied to cities, as seen with a decreasing correlation over the last 40 years, the world's largest cities have maintained their role both in terms of traffic volume, share, and centrality.

Our contribution wishes to provide additional evidence to the necessity for spatial network studies (and network analysis in general) not to ignore the socio-economic dimension of the connected nodes (here, population or demographic size) in order to verify the uneven territorial overlap between networks and cities. Among other results, we demonstrated that port cities, the "frontlines of globalization", have lost their explaining power about maritime traffic volumes. But the comparison of four different perspectives (c.f. two different definitions of the city and of the network) helped us to balance such a claim - that cities no longer need a port to growh and vice-versa - since we clearly proved that expanding the spatial unit of reference (from the sole port city to the extend city-region) and adapting the network's definition to this specific context both greatly improved our results and modified the way port cities should be understood today. Ports are still tied to cities and cities still need ports to growth and develop, but not through the same spatial and functional mechanisms than in the past, i.e. before and during the spread of containerization.

Further research is underway to integrate the global road transport network to the global maritime network in order to study how are cities performing in the combined land-sea network, thereby contributing to multiplex network studies. Another research pathway is to go beyond the sole population size but other variables such as urban Gross Domestic Product or employment structure are hard to obtain and often not harmonized globally across the different countries. Are richer and more productive cities more central? Before diving into the widening of our analysis, we believe that this chapter contributes to both urban, transport, and network studies by further bridging them together, given the fact that they too often stand apart. This step forward towards a better understanding of the spatiality of physical, non-planar networks is also a positive response to Schwanen (2017), rightly observing that most of the time, urban networks are studied without cities are nodes but other spatial units, in an abstract, topological space, by geographers as well as by other scientists.

\section{Acknowledgements}

The research leading to these results has received funding from the European Research Council under the European Union's Seventh Framework Programme (FP/2007-2013) / ERC Grant Agreement n. [313847] "World Seastems". 


\section{References}

Bernhofen D.M., El-Sahli Z., Kneller R. (2013) Estimating the effects of the container revolution on world trade. Lund University Working Paper 2013:4, Department of Economics, School of Economics and Management.

Bretagnolle A. (2015) City systems and maritime transport in the long term. In: Ducruet C. (Ed.), Maritime Networks. Spatial Structures and Time Dynamics, London and New York: Routledge Studies in Transport Analysis, pp. 27-36.

Bretagnolle A., Pumain D., Rozenblat C. (1998) Space-time contraction and the dynamics of Urban Systems. Cybergeo: European Journal of Geography, 61: https://journals.openedition.org/cybergeo/373

Bunel M., Bahoken F., Ducruet C., Lagesse C., Marnot B., Mermet E., Petit S. (2017) Geovisualizing the sail-to-steam transition through vessel movement data, In: Ducruet C. (Ed.), Advances in Shipping Data Analysis and Modeling. Tracking and Mapping Maritime Flows in the Age of Big Data, London and New York: Routledge Studies in Transport Analysis, pp. 189-205.

Cattan N. (1995) Barrier effects: The case of air and rail flows. International Political Science Review, 16(3): 237-248.

Cullinane K.P.B., Khanna M. (2000) Economies of scale in large containerships: Optimal size and geographical implications. Journal of Transport Geography, 8(3): 181-195.

Deng W.B., Long G., Wei L., Xu C. (2009) Worldwide marine transportation network: Efficiency and container throughput. Chinese Physics Letters, 26(11): 118901.

Ducruet C., Beauguitte L. (2014) Network science and spatial science: Review and outcomes of a complex relationship. Networks and Spatial Economics, 14(3-4): 297-316.

Ducruet C., Cuyala S., El Hosni A. (2018) Maritime networks as systems of cities: The long-term interdependencies between global shipping flows and urban development (1890-2010). Journal of Transport Geography, 66: 340-355.

Ducruet C., letri D., Rozenblat C. (2011) Cities in worldwide air and sea flows: A multiple networks analysis. Cybergeo: European Journal of Geography, 528, http://cybergeo.revues.org/23603

Ducruet C., Itoh H. (2016) Regions and material flows: Investigating the regional branching and industry relatedness of port traffic in a global perspective. Journal of Economic Geography, 16(4): 805-830.

Ducruet C., Lugo I. (2013) Cities and transport networks in shipping and logistics research. Asian Journal of Shipping and Logistics, 29(2): 149-170.

Ducruet C., Notteboom T.E. (2012) The worldwide maritime network of container shipping: Spatial structure and regional dynamics. Global Networks, 12(3): 395-423.

El Hosni A. (2017) Le retour du port dans la ville. Sarrebruck: Editions Universitaires Européennes.

Fleming D.K., Hayuth Y. (1994) Spatial characteristics of transportation hubs: Centrality and Intermediacy. Journal of Transport Geography, 2(1): 3-18.

Frémont A. (2007) Le monde en boîtes. Conteneurisation et mondialisation. Synthèse INRETS, 53, Arcueil: INRETS, $145 \mathrm{p}$. 
Guerrero D. (2014) Deep-sea hinterlands: Some empirical evidence of the spatial impact of containerization. Journal of Transport Geography, 35: 84-94.

Guerrero D., Rodrigue J.P. (2014) The waves of containerization: Shifts in global maritime transportation. Journal of Transport Geography, 35: 151-164.

Halim R.A., Kwakkel J.H., Tavasszy L.A. (2016) A strategic model of port-hinterland freight distribution networks. Transportation Research Part E, 95: 368-384.

Hayuth Y. (1981) Containerization and the load center concept. Economic Geography, 57(2): 160-176.

Hesse M. (2013) Cities and flows: Re-asserting a relationship as fundamental as it is delicate. Journal of Transport Geography, 29: 33-42.

Hu Y., Zhu D. (2009) Empirical analysis of the worldwide maritime transportation network. Physica A, 388(10): 2061-2071.

IRSIT (2004) Les Villes Portuaires en Europe. Analyse Comparative. Institut de Recherche en Stratégie Industrielle et Territoriale (IRSIT), https://www.mgm.fr/PUB/IRSIT.pdf

Jacobs W., Koster H.R.A., Hall P.V. (2011) The location and global network structure of maritime advanced producer services. Urban Studies, 48(13): 2749-2769.

Lee S.W., Ducruet C. (2009) Spatial glocalization in Asia-Pacific hub port cities: A comparison of Hong Kong and Singapore. Urban Geography, 30(2): 162-184.

Lee S.W., Song D.W., Ducruet C. (2008) A tale of Asia's world ports: The spatial evolution in global hub port cities, Geoforum, 39(1): 372-385.

Levinson M. (2008) The Box: How the Shipping Container Made the World Smaller and the World Economy Bigger. Princeton: Princeton University Press, $400 \mathrm{p}$.

Merk O. (2013) The Competitiveness of Global Port-Cities. Synthesis Report, Paris: OECD.

Merk O., Manshanden W.J.J., Dröes M.I. (2013) Inter-regional spillovers of seaports: The case of Northwest Europe. International Journal of Transport Economics, 40(3): 401-417.

Mohamed-Chérif F.Z., Ducruet C. (2016) Regional integration and maritime connectivity across the Maghreb seaport system. Journal of Transport Geography, 51: 280-293.

Morel J.C., Ducruet C. (2015) Interview - The man who brought containerisation to Europe. Portus Online, 29: http://portusonline.org/fr/interview-the-man-who-brought-containerisation-to-europe/

Notteboom T.E. (2004) Container shipping and ports: An overview. Review of Network Economics, 3(2): 86-106.

Notteboom T.E. (2016) The adaptive capacity of container ports in an era of mega vessels: The case of upstream seaports Antwerp and Hamburg. Journal of Transport Geography, 54: 295-309.

Parshani R., Rozenblat C., letri D., Ducruet C., Havlin S. (2010) Inter-similarity between coupled networks. Europhysics Letters (EPL), 92: 68002.

Pumain D., Paulus F., Vacchiani-Marcuzzo C. (2009) Innovation cycles and urban dynamics. In: Lane D., Pumain D., van der Leeuw S.E., West G. (Eds.), Complexity Perspectives in Innovation and Social Change, Springer, Methodos Series, Vol. 7, pp. 237-260. 
Rivers R., Evans T., Knappett C. (2015) From oar to sail. The role of technology and geography in the evolution of Bronze Age Mediterranean networks, In: Ducruet C. (Ed.), Maritime Networks. Spatial Structures and Time Dynamics, London and New York: Routledge Studies in Transport Analysis, pp. 6376.

Rodrigue J.P., Notteboom T.E. (2010) Foreland-based regionalization: Integrating intermediate hubs with port hinterlands. Research in Transportation Economics, 27(1): 19-29.

Rozenblat, C., Mélançon, G. (2013) Methods for Multilevel Analysis and Visualization of Geographical Networks, Springer Geography, Methodos Series, Vol. 11.

Rozenblat C., Pumain D. (1993) The location of multinational firms in the European urban system. Urban Studies, 30(10): 1691-1709.

Schwanen T. (2017) Geographies of transport II: Reconciling the general and the particular. Progress in Human Geography, 41(3): 355-364.

Slack B. (1993) Pawns in the game: Ports in a global transportation system. Growth and Change, 24(4): 579-588.

Slack B., Gouvernal E. (2015) Container transshipment and logistics in the context of urban economic development. Growth and Change, 47(3): 406-415.

Slack B., Wang J.J. (2002) The challenge of peripheral ports: An Asian perspective. Geojournal, 56(2): 159-166.

Stopford M. (2008) Maritime Economics. Abingdon: Routledge.

Tsiotas D., Polyzos S. (2018) Effects in the network topology due to node aggregation: Empirical evidence from the domestic maritime transportation in Greece. Physica A, 491: 71-88.

UNCTAD (2017) Review of Maritime Transport. Geneva: United Nations Conference on Trade and Development. 


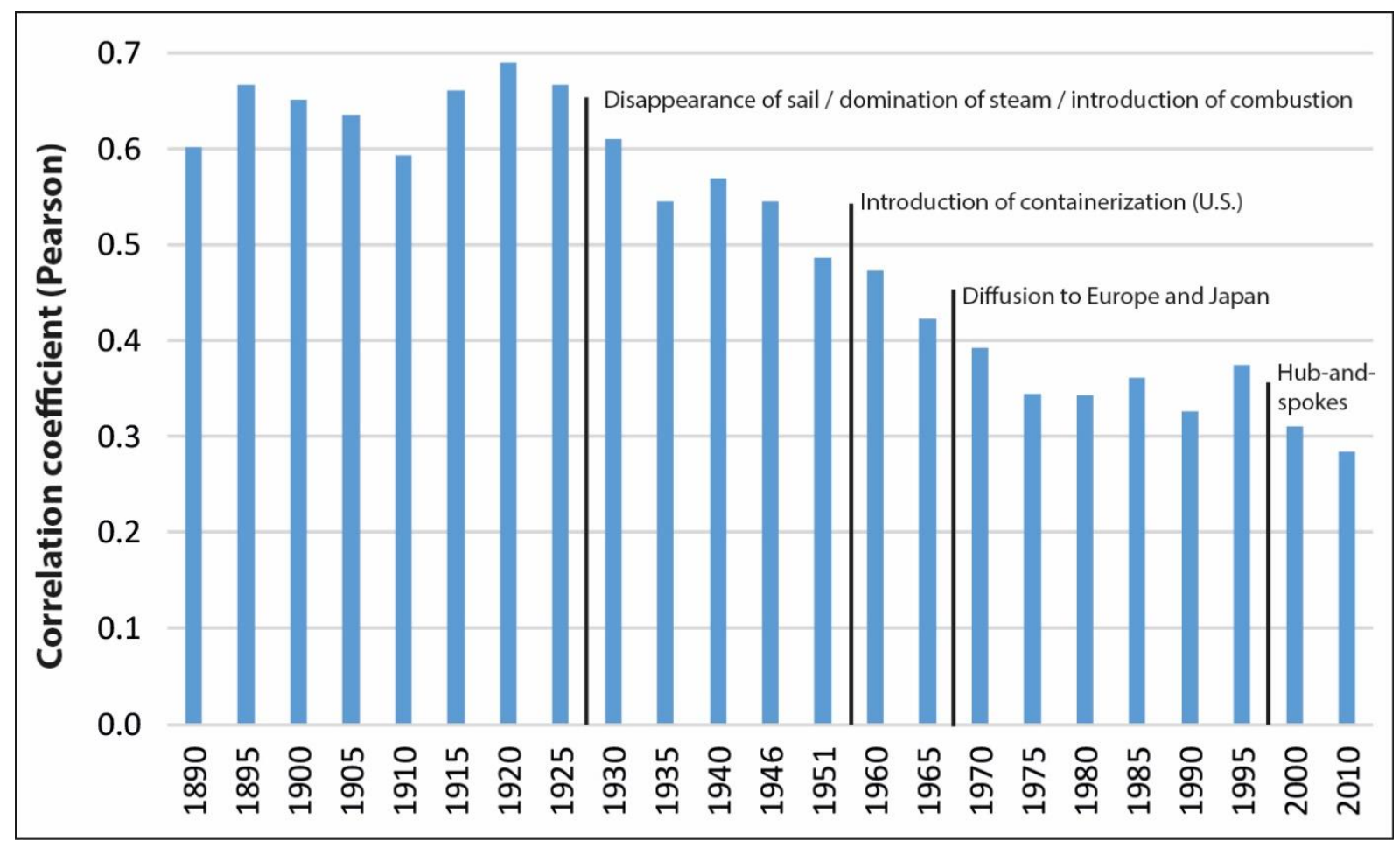

Figure 1: Technological change and port-city correlation, 1890-2010

Source: own elaboration based on Ducruet et al. (2018) 


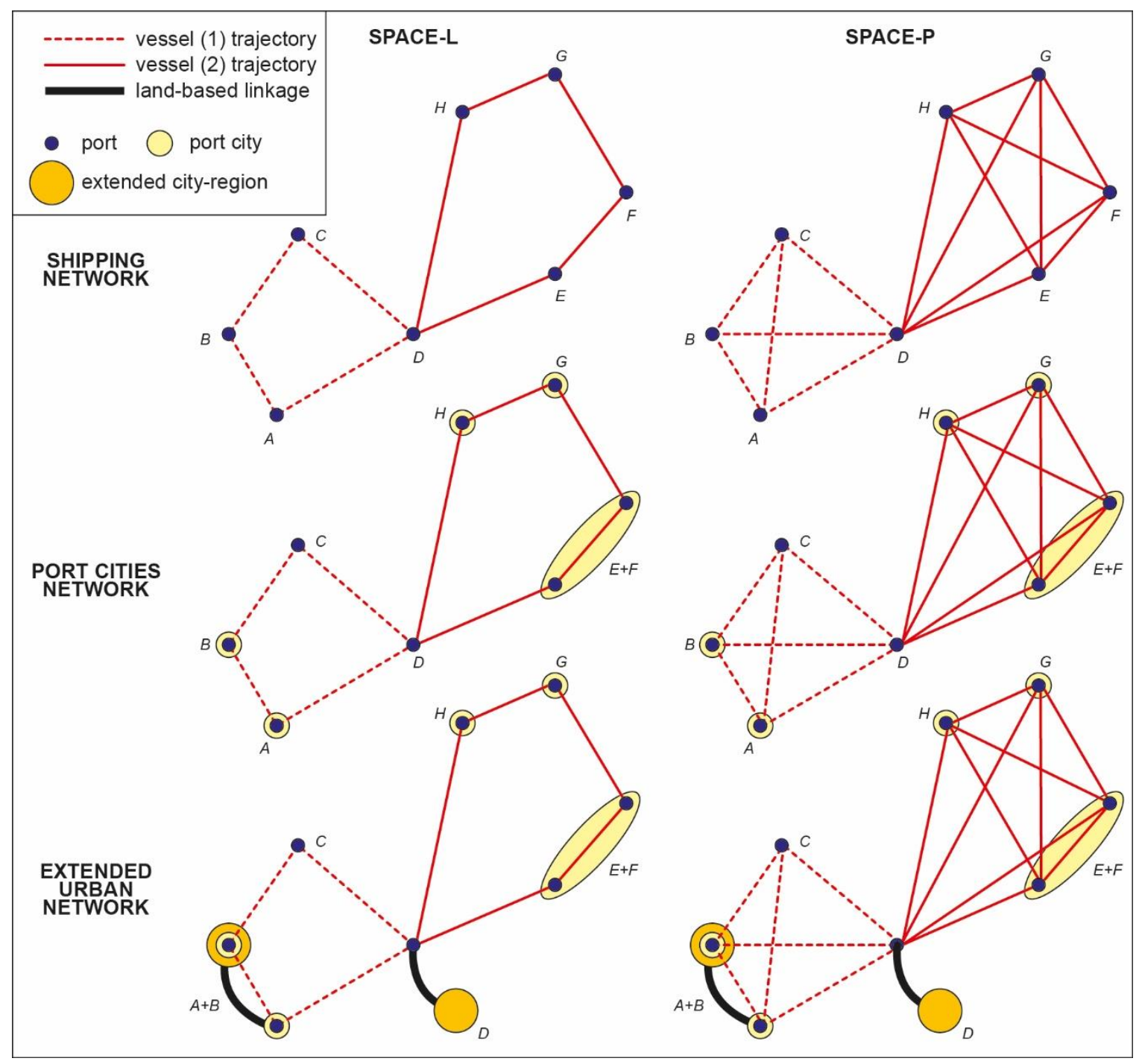

Figure 2: Various urban and topological perspectives on container shipping networks

Source: own elaboration based on Hu and Zhu (2009) 


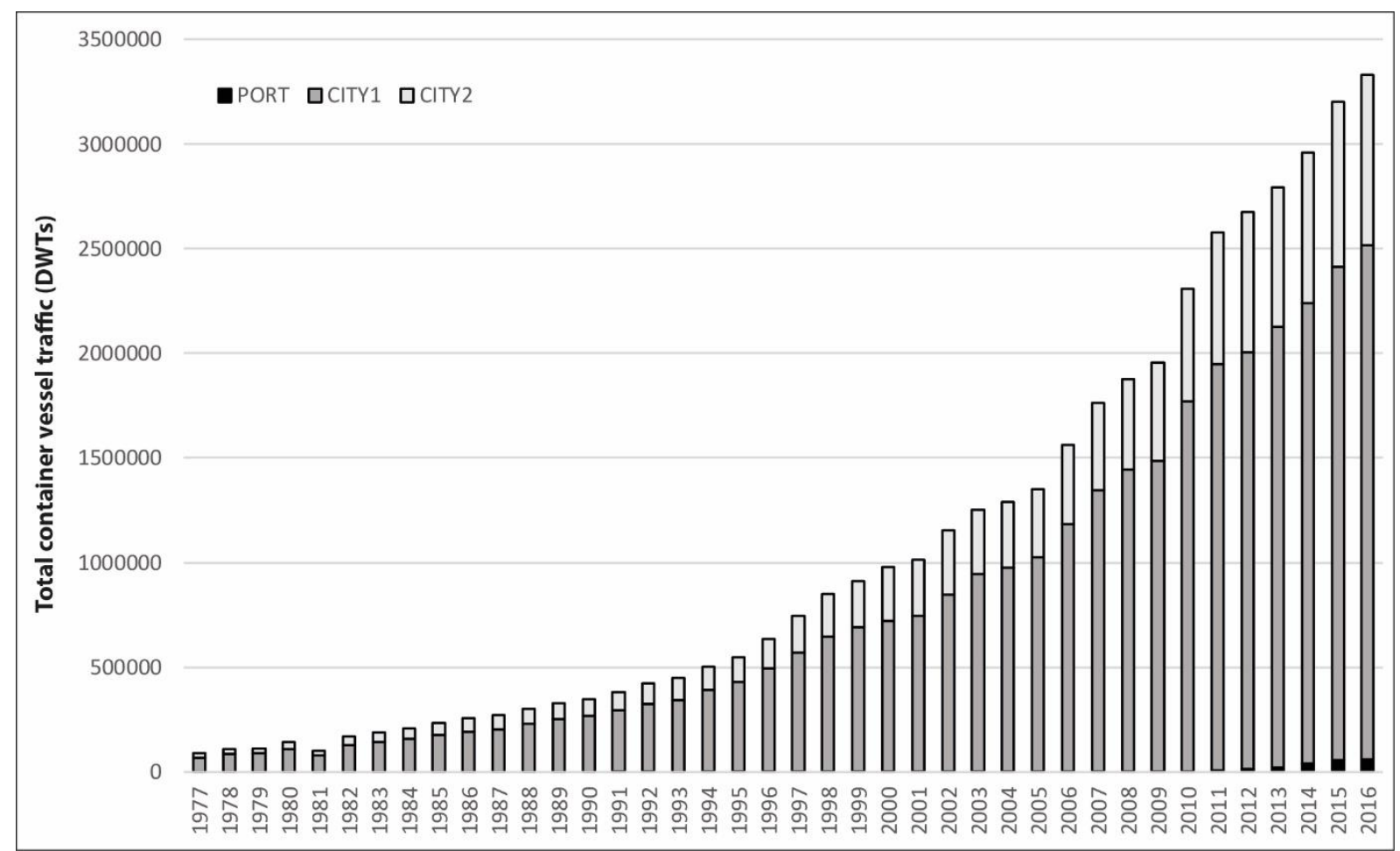

Figure 3: Container traffic distribution by place type, 1977-2016

Source: own elaboration 


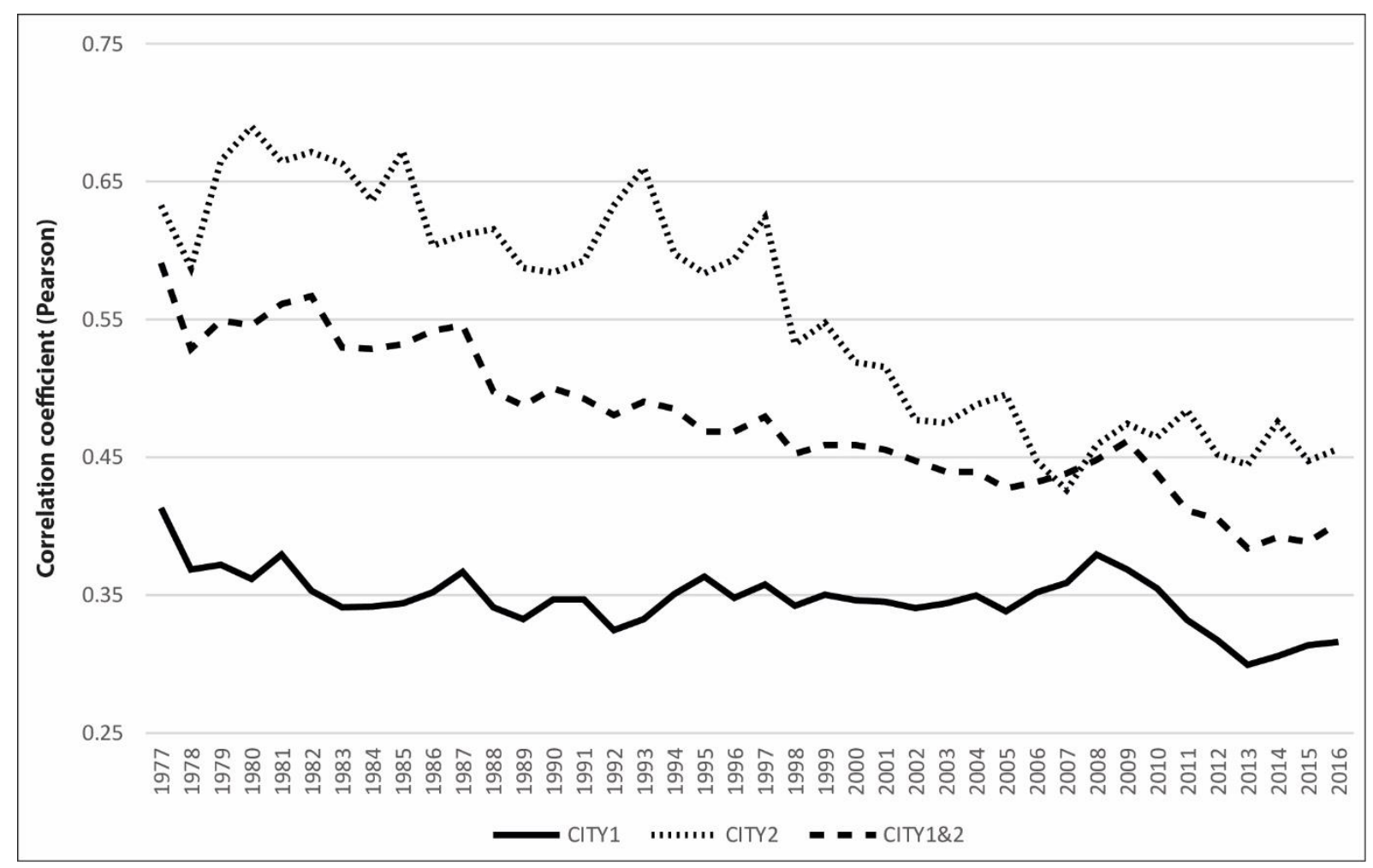

Figure 4: Correlation between urban population and container traffic, 1977-2016

Source: own elaboration 


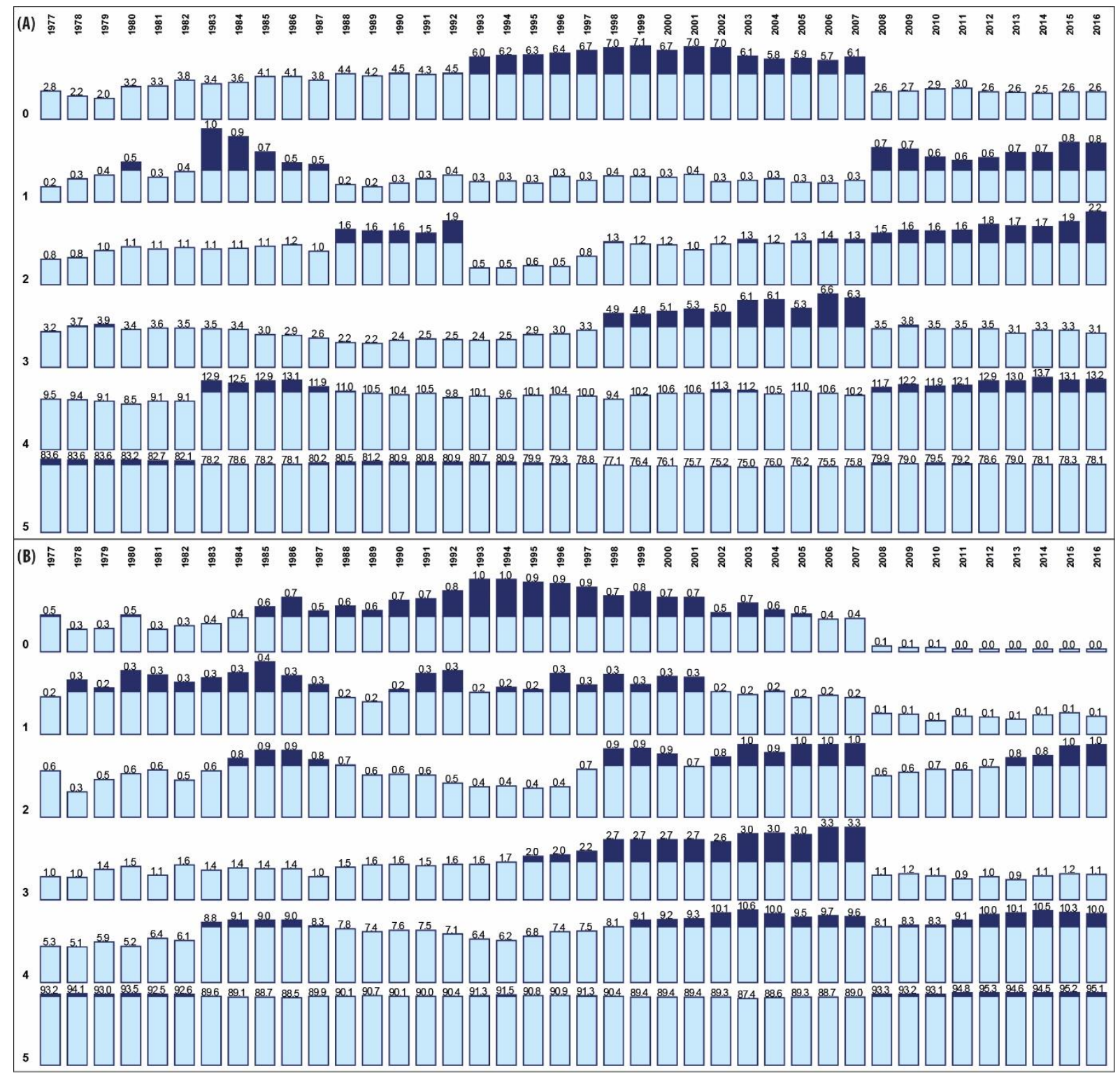

Figure 5: Container traffic distribution by demographic quantile, 1977-2016

N.B. port cities (A), extended city-regions \& port cities (B); non-urban ports (0), small city size (1), moderate city size (2), average city size (3), important city size (4), largest city size (5)

Source: own elaboration 


\begin{tabular}{|c|c|c|c|c|c|c|}
\hline \multirow{2}{*}{\multicolumn{2}{|c|}{ Measures }} & \multirow{3}{*}{$\begin{array}{c}\text { Year } \\
1977\end{array}$} & \multicolumn{2}{|c|}{ Space-L } & \multicolumn{2}{|c|}{ Space-P } \\
\hline & & & \multirow{2}{*}{$\begin{array}{l}\text { CITY1 } \\
0,364\end{array}$} & \multirow{2}{*}{$\begin{array}{c}\text { CITY1\&2 } \\
0,369\end{array}$} & \multirow{2}{*}{$\begin{array}{l}\text { CITY1 } \\
0,406\end{array}$} & \multirow{2}{*}{$\frac{\text { CITY1\&2 }}{0,456}$} \\
\hline \multirow{20}{*}{ 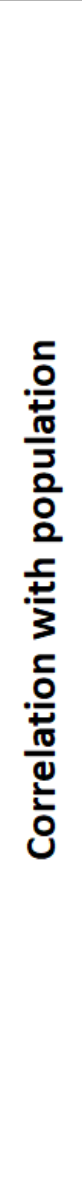 } & \multirow{5}{*}{ 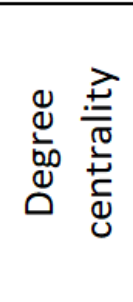 } & & & & & \\
\hline & & 1987 & 0,312 & 0,317 & 0,331 & 0,382 \\
\hline & & 1997 & 0,453 & 0,453 & 0,427 & 0,476 \\
\hline & & 2007 & 0,376 & 0,362 & 0,478 & 0,498 \\
\hline & & 2016 & 0,401 & 0,401 & 0,422 & 0,445 \\
\hline & \multirow{5}{*}{ 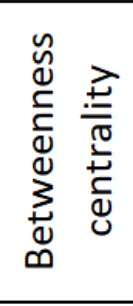 } & 1977 & 0,226 & 0,233 & 0,237 & 0,410 \\
\hline & & 1987 & 0,223 & 0,228 & 0,180 & 0,350 \\
\hline & & 1997 & 0,279 & 0,280 & 0,248 & 0,332 \\
\hline & & 2007 & 0,230 & 0,225 & 0,284 & 0,348 \\
\hline & & 2016 & 0,207 & 0,209 & 0,269 & 0,318 \\
\hline & \multirow{5}{*}{ 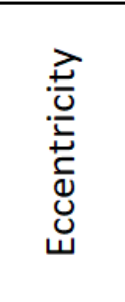 } & 1977 & $-0,051$ & $-0,056$ & $-0,310$ & $-0,175$ \\
\hline & & 1987 & $-0,069$ & $-0,081$ & $-0,238$ & $-0,297$ \\
\hline & & 1997 & $-0,188$ & $-0,189$ & $-0,308$ & $-0,378$ \\
\hline & & 2007 & $-0,245$ & $-0,234$ & $-0,321$ & $-0,346$ \\
\hline & & 2016 & $-0,261$ & $-0,258$ & $-0,343$ & $-0,328$ \\
\hline & \multirow{5}{*}{ 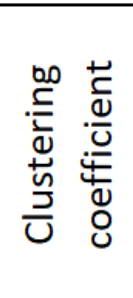 } & 1977 & 0,252 & 0,254 & 0,241 & 0,390 \\
\hline & & 1987 & 0,188 & 0,193 & 0,233 & 0,352 \\
\hline & & 1997 & 0,304 & 0,305 & 0,371 & 0,451 \\
\hline & & 2007 & 0,247 & 0,229 & 0,284 & 0,424 \\
\hline & & 2016 & 0,234 & 0,232 & 0,346 & 0,394 \\
\hline
\end{tabular}

Figure 6: Correlation (Pearson) between centralities and population at selected years, 1977-2016 N.B. based on the inverse value of the clustering coefficient

Source: own elaboration 


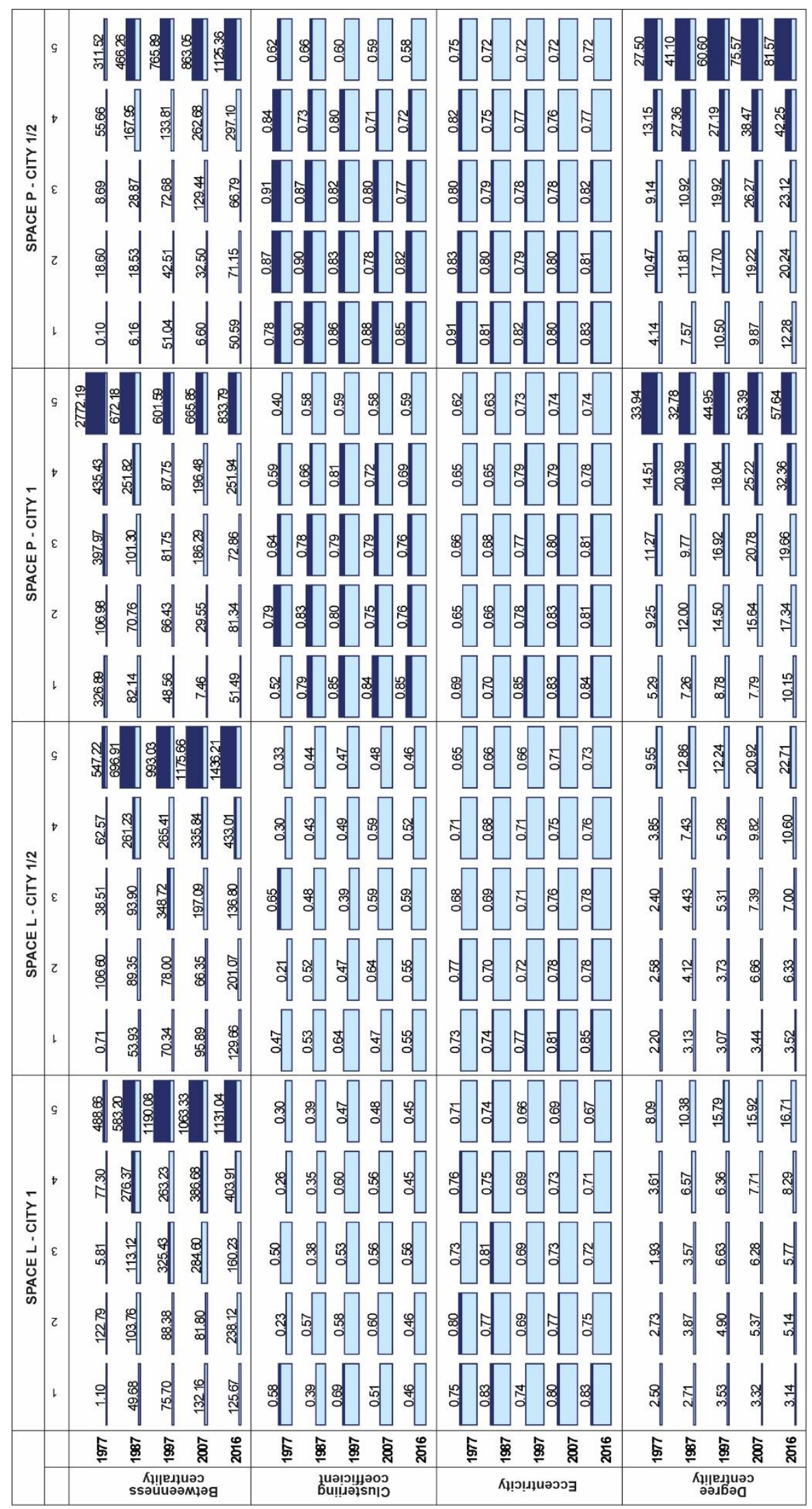

Figure 7: Average centrality per population quantile at selected years, 1977-2016

Source: own elaboration 


\begin{tabular}{|c|c|c|c|c|c|c|c|c|c|}
\hline City & 1977 & City & 1987 & City & 1997 & City & 2007 & City & 2016 \\
\hline Osaka & 6095395 & Osaka & 19563383 & Hong Kong & 57131846 & Hong Kong & 116665822 & Singapore & 162766699 \\
\hline Tokyo & 5839131 & Tokyo & 19349285 & Singapore & 52916822 & Singapore & 96641506 & Shenzhen & 156797205 \\
\hline Rotterdam & 4435547 & Hong Kong & 17151634 & Tokyo & 35419105 & Shanghai & 72886371 & Shanghai & 152681263 \\
\hline Hong Kong & 4404215 & Kaohsiung & 11332338 & Osaka & 30480647 & Shenzhen & 62459603 & Hong Kong & 119869974 \\
\hline New York & 3996619 & Rotterdam & 10879412 & Kaohsiung & 30019133 & Busan & 60577372 & Ningbo & 103395326 \\
\hline Bremen & 3187762 & Taipei & 10476247| & London & 22640708 & Tokyo & 49914010 & Busan & 102458199 \\
\hline Los Angeles & 3163848 & Busan & 10366831 & Busan & 22220108 & Kaohsiung & 46907471 & Qingdao & 91026532 \\
\hline London & 3037651 & Nagoya & 8651655 & Rotterdam & 20999826 & $\begin{array}{l}\text { Kuala } \\
\text { Lumpur }\end{array}$ & 42603937 & Kuala Lumpur & 74747413 \\
\hline Hamburg & 2908135 & London & 8592861 & Nagoya & 16515991 & Rotterdam & 36931953 & Kaohsiung & 62353438 \\
\hline Le Havre & 2554225 & Los Angeles & 8042520 & Los Angeles & 15770111 & London & 36256987 & Rotterdam & 55746419 \\
\hline Nagoya & 2382368 & Hamburg & 7169989 & Le Havre & 12256797 & Osaka & 31220784 & Tokyo & 53959894 \\
\hline San Francisco & 2309653 & Le Havre & 6688253 & Hamburg & 12227335 & Ningbo & 31200486 & London & 47488998 \\
\hline Singapore & 2299814 & New York & 6294237 & $\begin{array}{l}\text { Kuala } \\
\text { Lumpur }\end{array}$ & 12214657 & Hamburg & 29139084 & Dubai & 46549165 \\
\hline Baltimore & 2001996 & $\begin{array}{l}\text { San } \\
\text { Francisco }\end{array}$ & 5445161 & Taipei & 11727859 & Los Angeles & 28349584 & Xiamen & 45633545 \\
\hline Kaohsiung & 1579028 & Bremen & 5403756 & New York & 11592911 & Antwerp & 27894892 & Antwerp & 44422867 \\
\hline Kuala Lumpur & 1557418 & Antwerp & 4727480 & \begin{tabular}{|l} 
San \\
Francisco
\end{tabular} & 10578176 & Qingdao & 25249995 & $\begin{array}{l}\text { Johore } \\
\text { Baharu }\end{array}$ & 39568214 \\
\hline Charleston & 1537925 & Seattle & 3796055 & Colombo & 10465553 & Dubai & 24170231 & Bangkok & 38108709 \\
\hline Philadelphia & 1365134 & Jiddah & 3650991 & Antwerp & 9787841 & Nagoya & 22107710 & Guangzhou & 36742338 \\
\hline Sydney & 1163716 & Singapore & 3549919 & Bangkok & 9165413 & Xiamen & 21659488 & Colombo & 35703373 \\
\hline Marseille & 1071976 & Charleston & 2874917 & Charleston & 8476277 & New York & 21655539 & Hamburg & 35051619 \\
\hline
\end{tabular}

\section{Appendix 1: Total container traffic of the top 20 extended city-regions at selected years, 1977-2016}

Source: own elaboration (unit: deadweight tons - DWT) 


\begin{tabular}{|c|c|c|c|c|c|}
\hline & Quantile & $\mathrm{Nb}$. & Avg. & Min. & Max. \\
\hline \multirow{5}{*}{1977} & 1 & 400 & 10 & 1 & 18 \\
\hline & 2 & 397 & 28 & 19 & 39 \\
\hline & 3 & 451 & 60 & 40 & 87 \\
\hline & 4 & 433 & 141 & 88 & 229 \\
\hline & 5 & 423 & 1166 & 230 & 23863 \\
\hline \multirow{5}{*}{1987} & 1 & 430 & 11 & 1 & 20 \\
\hline & 2 & 425 & 32 & 21 & 47 \\
\hline & 3 & 433 & 73 & 48 & 107 \\
\hline & 4 & 433 & 176 & 108 & 293 \\
\hline & 5 & 432 & 1434 & 294 & 27358 \\
\hline \multirow{5}{*}{1997} & 1 & 439 & 11 & 1 & 23 \\
\hline & 2 & 441 & 36 & 23 & 51 \\
\hline & 3 & 442 & 81 & 52 & 119 \\
\hline & 4 & 443 & 199 & 120 & 329 \\
\hline & 5 & 442 & 1638 & 330 & 31594 \\
\hline \multirow{5}{*}{2007} & 1 & 437 & 12 & 1 & 24 \\
\hline & 2 & 435 & 39 & 25 & 55 \\
\hline & 3 & 482 & 89 & 56 & 136 \\
\hline & 4 & 406 & 224 & 136 & 372 \\
\hline & 5 & 443 & 1926 & 373 & 35691 \\
\hline \multirow{5}{*}{2016} & 1 & 580 & 3 & 1 & 9 \\
\hline & 2 & 650 & 17 & 9 & 29 \\
\hline & 3 & 621 & 48 & 30 & 74 \\
\hline & 4 & 625 & 135 & 75 & 240 \\
\hline & 5 & 620 & 1559 & 241 & 36933 \\
\hline
\end{tabular}

Appendix 2: Description of population quantiles at selected years, 1977-2016

Source: own elaboration 


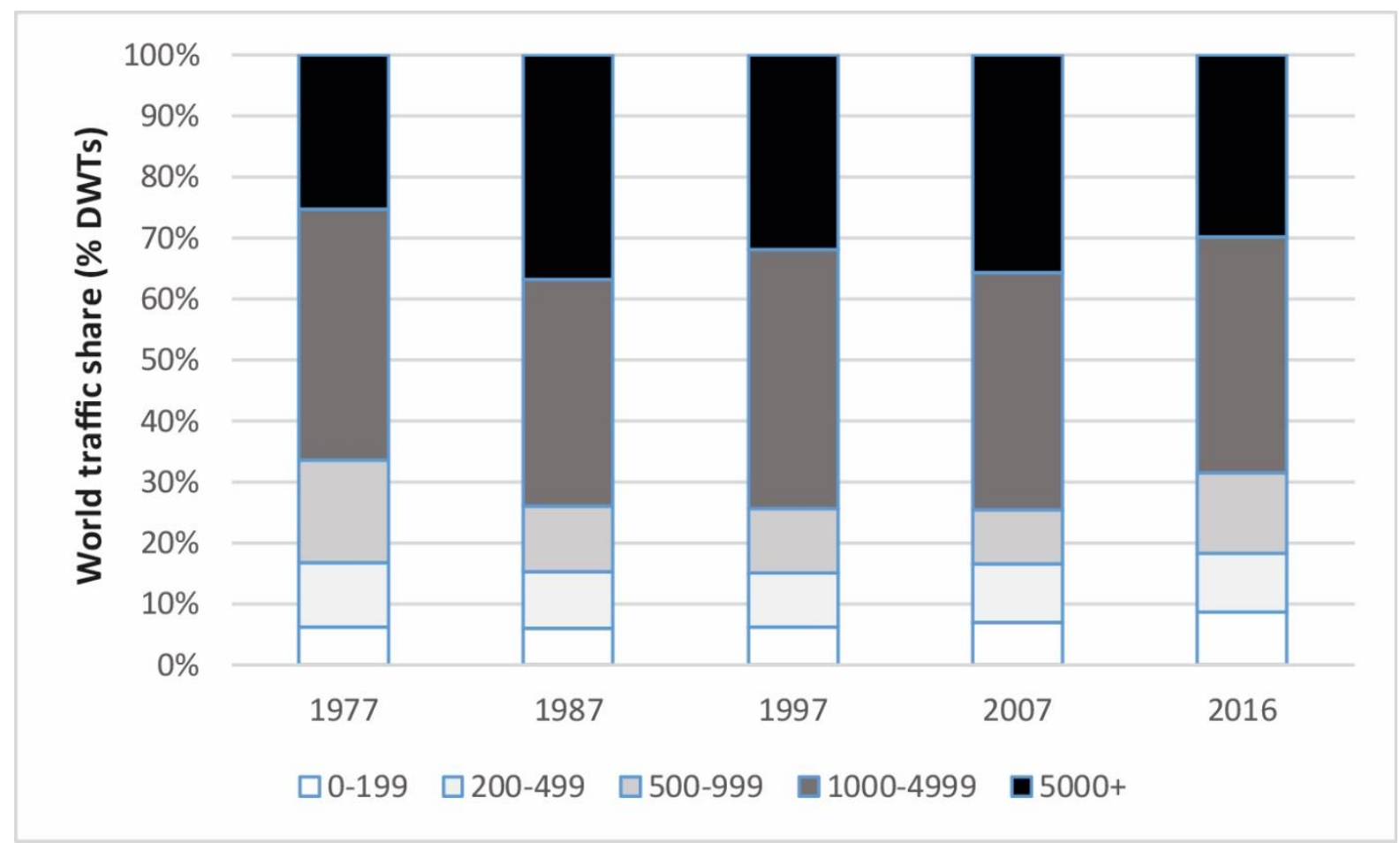

Appendix 3: Container traffic distribution per population classes at selected years, 1977-2016 Source: own elaboration 